Check for updates

Cite this: RSC Adv., 2019, 9, 32288

Received 31st August 2019 Accepted 1st October 2019

DOI: $10.1039 / c 9 r a 06920 h$

rsc.li/rsc-advances

\section{Three chiral one-dimensional lanthanide- ditoluoyl-tartrate bifunctional polymers exhibiting luminescence and magnetic behaviors $\uparrow$}

\author{
Mei-rong Han, (iD ta Han-tao Zhang, t $^{a}$ Jia-nan Wang, ${ }^{a}$ Si-si Feng (iD *ab \\ and Li-ping Lu iD *ab
}

Since Ln-CPs have excellent optical properties (higher color purity, longer fluorescence lifetime and higher quantum yield) and magnetic properties, it is of great significance to prepare dual magneto-optical materials based on $\mathrm{Ln}(\mathrm{II})$. Herein, we obtained three versatile $\mathrm{Ln}-\mathrm{CPS}$, $\left[\mathrm{Ln}(\mathrm{HDTTA})_{3}\left(\mathrm{CH}_{3} \mathrm{OH}\right)_{3}\right]_{n}$, derived from reactions of lanthanide salts ( $\mathrm{Ln}=\mathrm{Tb} 1$, Dy 2, Ho 3) and a chiral and flexible ligand, namely, (+)-dip-toluoyl-D-tartaric acid ( $d-\mathrm{H}_{2}$ DTTA) in a methanol-water solution, at room temperature and pressure. The structures of these compounds have been characterized by single crystal and powder $\mathrm{X}$-ray diffraction, infrared spectroscopy, elemental analyses and thermogravimetric analyses. Complexes 1-3 are isomorphic, crystallizing in the chiral trigonal $R 3$ space group with the linkage of $\mathrm{Ln}^{3+}$ ions and featuring $1 \mathrm{D}$ propeller chain structures. The circular dichroism spectra confirm that the complexes maintain the chirality from the ligands. Furthermore, the luminescent and magnetic properties have been investigated, relying on intrinsic properties of the lanthanide ions. The photoluminescence measurements indicate that 1, 2 and 3 show strong green, white and blue emission bands with $\mathrm{CIE}$ chromaticity coordinates of $(0.32,0.56),(0.29,0.26)$ and $(0.21,0.12)$, respectively. The decay lifetime curve of 1 shows the exponential decay with long lifetime of $1.169 \mathrm{~ms}$ and the relative quantum yield for 1 was $19.31 \%$. In addition, the magnetic properties of complexes $1-3$ have been investigated by measuring the magnetic susceptibility in the temperature range of 2-300 K. They are all dominated by spin-orbit coupling and ligand field perturbation, and the exchange coupling between $\mathrm{Ln}^{3+}$ ions is almost negligible. Therefore, complexes 1-3 are promising chiral, optical and magnetic multifunctional materials.

\section{Introduction}

In recent years, the rational design and syntheses of lanthanide coordination polymers (Ln-CPs) have attracted much attention due to their fascinating architectures and unique chemical and physical properties, especially optical and magnetic. ${ }^{-4}$ A huge number of Ln-CPs have been investigated in luminescence fields due to their advantages of narrow emission spectra, good

\footnotetext{
${ }^{a}$ Institute of Molecular Science, Key Laboratory of Chemical Biology and Molecular Engineering of the Education Ministry, Shanxi University, Taiyuan, Shanxi 030006, P. R. China. E-mail: ssfeng@sxu.edu.cn; luliping@sxu.edu.cn; Fax: +86-3517011022; Tel: +86-351-7017974

${ }^{b}$ Key Laboratory of Materials for Energy Conversion and Storage of Shanxi Province, Shanxi University, Taiyuan, Shanxi, 030006, P. R. China

$\dagger$ Electronic supplementary information (ESI) available. CCDC X-ray crystallographic data for compounds 1-3 in CIF format (CCDC 1940269, 1939982 and 1939983), selected bond lengths and bond angles, the figures of IR spectra, PXRD patterns, TGA plots, and molar magnetization figures are presented. For ESI and crystallographic data in CIF or other electronic format see DOI: $10.1039 / \mathrm{c} 9 \mathrm{ra} 06920 \mathrm{~h}$

$\$$ These authors contribute equally to this work.
}

monochrome light performance, long luminescence lifetimes (milliseconds), high photoluminescence (PL) efficiency and large Stokes shifts. ${ }^{5-8}$ Compared to CPs based on transition metal ions, Ln-CPs have larger coordination spheres ${ }^{9}$ and more fascinating coordination geometries, ${ }^{\mathbf{1 0}}$ which are especially beneficial for luminescent materials, because the luminescence intensity of lanthanide ions is very sensitive to structural details of the coordination environment. Beside luminescent properties, lanthanide ions also exhibit large magnetic moment and strong magnetic anisotropy, which could have potential applications in spintronics, quantum computing and information storage. ${ }^{\mathbf{1 1 , 1 2}}$ So, lanthanide ions are good candidates for developing advanced multifunctional materials, which can incorporate both photoluminescent centers and magnetic properties simultaneously. Several classes of ligands such as cryptands, ${ }^{13}$ $\beta$-diketone, ${ }^{\mathbf{1 4}}$ and carboxylic acid $^{\mathbf{1 5}}$ have been utilized to construct multifunctional Ln-CPs. Among all types of ligands, aromatic polycarboxylate ligands are most frequently used due to their plentiful coordination points, strong interactions with the lanthanide ions and various coordination modes, as well as the structuring effect through $\pi$ stacking and hydrogen 
bonding. Moreover, aromatic polycarboxylate ligands may carry out multiple functions because they can be used as blue color sources and outstanding sensitizers to activate $\mathrm{Ln}^{3+}$ ions, ${ }^{\mathbf{1 6 - 1 9}}$ and they can serve as mediators of the exchange spin coupling between metal ions by bridging carboxylate groups. ${ }^{20}$

For the past few years, we have been working on Ln-CPs constructed by aromatic polycarboxylate ligands. ${ }^{21-23}$ As the following studies on this system, in the present work, we focus on novel Ln-CPs employing a chiral and flexible ligand, namely, ditoluoyl-tartaric acid ( $\mathrm{H}_{2}$ DTTA). This flexible dicarboxylic acid has two equal chiral carbon atoms, and the variable coordination modes provided by this carboxyl-rich molecule can lead to the isolation of metallo-organic hybrid topologies with multiple metal centers. ${ }^{24,25}$ Although the crystal structures of several ditoluoyl-tartrate metal/ammonium salts ${ }^{26-30}$ have been documented, however, only calcium, ${ }^{31}$ Ln (La, Nd, Eu, Gd and $\mathrm{Tb}),{ }^{32,33}$ and $\mathrm{Ln} / \mathrm{K}(\mathrm{Ln}=\mathrm{Dy}-\mathrm{Lu})$ complexes $^{34}$ based $1-\mathrm{H}_{2}$ DTTA have been reported. The coordination features and chemical properties of ditoluoyl-tartrate still need to be explored. Moreover, to the best of our knowledge, lanthanide complexes of d$\mathrm{H}_{2}$ DTTA enantiomer are practically unexplored, thus offering a good opportunity to exploit the chiral, optical and magnetic properties in view of the generation of new materials.

In this contribution, we used d-type $(+)$-di- $p$-toluoyl-D-tartaric acid ( $\left.\mathrm{d}-\mathrm{H}_{2} \mathrm{DTTA}\right)$ and heavy lanthanide ions, and successfully prepared and structurally characterized three new coordination polymers, $\left[\operatorname{Ln}(\mathrm{HDTTA})_{3}\left(\mathrm{CH}_{3} \mathrm{OH}\right)_{3}\right]_{n}(\mathrm{Ln}=\mathrm{Tb} \mathbf{1}$, Dy 2, Ho 3). It is worth mentioning that these compounds have been obtained at room temperature and pressure, even though $\mathrm{Ln}^{3+}$ coordination compounds are often synthesized via solvothermal methods. ${ }^{35}$ The structures of these Ln-CPs have been solved by single crystal X-ray diffraction, which crystallized in the chiral $R 3$ space group, featuring $1 \mathrm{D}$ helical chain structure. Luminescence measurements show that upon excitation compound 1 mainly exhibits the characteristic transitions of corresponding $\mathrm{Tb}(\mathrm{III})$, and compound 2 exhibits white emissions originating from Dy(III) and the ligand, which evidences the presence of well-defined transitions characteristic for the considered lanthanide. The magnetic studies reveal that compounds 1-3 all exhibit the single ion magnetic behaviors. So these compounds are promising chiral, optical and magnetic multifunctional materials.

\section{Experimental section}

\subsection{Materials and methods}

The organic ligand $\mathrm{d}-\mathrm{H}_{2}$ DTTA was purchased from Jinan Henghua Sci. \& Tec. Co. Ltd, and used directly without further purification. All reagents and solvents were of standard commercial grade and directly used without further purification. IR spectra were obtained on a BRUKER TENSOR27 spectrometer with $\mathrm{KBr}$ disks. Samples for EA experiments were dried under vacuum, and the analyses were performed with a CHN-O-Rapid instrument. PXRD data were collected on a Bruker D8 Advance X-ray diffractometer with $\mathrm{Cu}-\mathrm{K} \alpha$ radiation $(\lambda=1.5418 \AA)$. Thermogravimetric analyses (TGA) were performed on a Dupont thermal analyzer with a heating rate of $10{ }^{\circ} \mathrm{C} \mathrm{min}^{-1}$ and under a nitrogen atmosphere. Circular dichroism (CD) spectra in the solid state were recorded with a JASCO J-810 dichrograph. The UV-vis diffuse reflectance spectra (DRS) were recorded by a TU-1950 spectrophotometer, and the wavelength ranged from 230-850 $\mathrm{nm}$. Luminescence analyses were performed on a Fluoromax-4 Spectrofluorometer with a xenon arc lamp as the light source. Luminescence lifetime measurements were carried out on a Quantaurus-Tau Compact Fluorescence Lifetime Spectrometer C11347, and the quantum yields were measured on a Quantaurus-QY Absolute PL Quantum Yield Spectrometer C11347. The formula $\Phi=\left(E_{\mathrm{c}}-E_{\mathrm{a}}\right) /\left(L_{\mathrm{a}}-L_{\mathrm{c}}\right)$ was used for calculation, in which $E_{\mathrm{c}}$ represents the strongest emission spectrum of the samples, $E_{\mathrm{a}}$ for the emission spectrum of the "blank" at the same excitation wavelength as the samples, $L_{\mathrm{c}}$ for the samples absorption at the excitation wavelength and $L_{\mathrm{a}}$ for the "blank" absorption at the same excitation wavelength as the samples. Magnetic susceptibility measurements data were obtained with SQUID magnetometer (Quantum MPMS) in the temperature range $2.0-300 \mathrm{~K}$ by using an applied field of 1000 Oe.

\subsection{Syntheses of $\left[\operatorname{Ln}(\mathrm{HDTTA})_{3}\left(\mathrm{CH}_{3} \mathrm{OH}\right)_{3}\right]_{n}(\operatorname{Ln}=\mathrm{Tb} 1$, Dy 2, Ho 3)}

A $2.50 \mathrm{~mL}$ methanol solution of $\mathrm{d}-\mathrm{H}_{2}$ DTTA $(69.50 \mathrm{mg}, 0.18$ $\mathrm{mmol}$ ) was added to a $25 \mathrm{~mL}$ round-bottom flask. A $2.50 \mathrm{~mL}$ aqueous solution of $\mathrm{TbCl}_{3} \cdot 6 \mathrm{H}_{2} \mathrm{O}$ or $\mathrm{Dy}\left(\mathrm{NO}_{3}\right)_{3} \cdot 5 \mathrm{H}_{2} \mathrm{O}(52.60 \mathrm{mg} /$ $54.30 \mathrm{mg}, 0.12 \mathrm{mmol}$ ) was added slowly to the solution. Then a $450 \mu \mathrm{L} \mathrm{KOH}\left(0.20 \mathrm{~mol} \mathrm{~L}^{-1}\right)$ was carefully added to the solution and the $\mathrm{pH}$ values of the reaction solutions are 3 , and 3.5 , respectively. After stirring $7 \mathrm{~h}$ at room temperature, the filtrate was left undisturbedly for one week. Colorless needle-shaped crystals of 1 or 2 were obtained in $27.0 \%$ or $28.0 \%$ yield respectively based on $\mathrm{d}-\mathrm{H}_{2}$ DTTA.

$\mathrm{EA}(\%)$ : calcd for $\mathrm{C}_{63} \mathrm{H}_{63} \mathrm{O}_{27} \mathrm{~Tb}(1)$ : C, 53.62; H, 4.50. Found: $\mathrm{C}$ 53.47, H 4.21. IR (KBr, $\left.\nu / \mathrm{cm}^{-1}\right): 3467 \mathrm{~s}, 2953 \mathrm{w}, 1734 \mathrm{~s}, 1708 \mathrm{~s}$, $1673 \mathrm{~s}, 1611 \mathrm{~s}, 1509 \mathrm{~m}, 1411 \mathrm{~m}, 1267 \mathrm{~s}, 1180 \mathrm{~s}, 1109 \mathrm{~s}, 1020 \mathrm{~m}$, 906w, 752s, 690w, 563w, 477w.

$\mathrm{EA}(\%)$ : calcd for $\mathrm{C}_{63} \mathrm{H}_{63} \mathrm{O}_{27} \mathrm{Dy}(2)$ : C, 53.49; H, 4.49. Found: $\mathrm{C}$ 53.13, H 4.28. IR (KBr, $\left.\nu / \mathrm{cm}^{-1}\right)$ : 3459s, 2953w, 1733s, 1709s, $1674 \mathrm{~s}, 1611 \mathrm{~s}, 1509 \mathrm{~m}, 1410 \mathrm{~m}, 1267 \mathrm{~s}, 1179 \mathrm{~s}, 1108 \mathrm{~s}, 1020 \mathrm{~s}, 906 \mathrm{w}$, $840 \mathrm{w}, 752 \mathrm{~s}, 690 \mathrm{w}, 563 \mathrm{w}, 477 \mathrm{w}$.

A $2.50 \mathrm{~mL}$ ethanol solution of $\mathrm{d}-\mathrm{H}_{2}$ DTTA $(69.50 \mathrm{mg}, 0.18$ mmol) was added to a $25 \mathrm{~mL}$ round-bottom flask. A $2.50 \mathrm{~mL}$ aqueous solution of $\mathrm{HoCl}_{3} \cdot 6 \mathrm{H}_{2} \mathrm{O}(45.50 \mathrm{mg}, 0.12 \mathrm{mmol})$ was added slowly to the solution. Then a $600 \mu \mathrm{L} \mathrm{KOH}\left(0.20 \mathrm{~mol} \mathrm{~L}^{-1}\right)$ was carefully added to the solution and the $\mathrm{pH}$ value of the reaction solution is 4 . After stirring $7 \mathrm{~h}$ at room temperature, the mixture was filtered and left undisturbedly for one week. Light pink needle-shaped crystals of 3 were obtained in $30.0 \%$ yield based on d- $\mathrm{H}_{2}$ DTTA. EA (\%): calcd for $\mathrm{C}_{63} \mathrm{H}_{63} \mathrm{O}_{27} \mathrm{Ho}$ (3): C, 53.40; H, 4.48. Found: C 53.31, H 4.27. IR ( $\left.\mathrm{KBr}, \nu / \mathrm{cm}^{-1}\right): 3462 \mathrm{~s}$, $2953 \mathrm{w}, 1734 \mathrm{~s}, 1708 \mathrm{~s}, 1674 \mathrm{~s}, 1611 \mathrm{~s}, 1509 \mathrm{~m}, 1411 \mathrm{~m}, 1338 \mathrm{~m}$, $1267 \mathrm{~s}, 1180 \mathrm{~s}, 1109 \mathrm{~s}, 1020 \mathrm{~s}, 906 \mathrm{w}, 841 \mathrm{w}, 752 \mathrm{~s}, 689 \mathrm{~m}, 563 \mathrm{w}$, $477 \mathrm{w}$.

\subsection{X-ray crystallography}

Single-crystal X-ray diffraction patterns for 1 were measured on a Bruker Smart Apex II diffractometer with a CCD area detector 
and Mo-K $\alpha$ radiation $(\lambda=0.71073 \AA)$ at room temperature. Single-crystal X-ray diffraction data for complexes 2 and 3 were collected at $100(2) \mathrm{K}$ in the Beijing Synchrotron Radiation Facility (BSRF) beam-line 3W1A, which was equipped with a MARCCD-165 detector $(\lambda=0.7000 \AA$ for 2 and $0.7200 \AA$ for 3 ) with the storage ring working at $2.5 \mathrm{GeV}$. Data were collected by the MARCCD diffractometer and processed by using HKL $2000 .{ }^{36}$ Multi-scan program SADABS was used for absorption correction. ${ }^{37}$ The structures were solved by the direct method and refined by the full-matrix least squares method on $F^{2}$ using the SHELXS-2014. ${ }^{38}$ All the non-H atoms were refined anisotropically. Hydrogen atoms attached to $\mathrm{C}$ and $\mathrm{N}$ atoms were placed geometrically and refined by using a riding model approximation, with $\mathrm{C}-\mathrm{H}=0.93-0.96 \AA$. Hydrogen atoms in hydroxyl and water molecules were located from difference Fourier maps and refined using their global $U_{\text {iso }}$ value with $\mathrm{O}-\mathrm{H}$ $=0.82 \AA$.

A summary of the crystallographic data as well as the data collection and refinement parameters for compounds $\mathbf{1 - 3}$ is provided in Table 1. Crystallographic data in CIF format are deposited with the Cambridge Crystallographic Data Center as CCDC 1940269, 1939982 and 1939983 for 1-3. Selected bond lengths and angles for 1-3 are provided in Table $\mathrm{S} 1 . \dagger$

\section{Results and discussion}

\subsection{Syntheses and characterization of 1-3}

The reaction routes of complexes 1-3 are shown in Scheme 1. The syntheses of 1-3 are $\mathrm{pH}$ dependent with the same reaction conditions, and the $\mathrm{pH}$ values of the reaction solutions are 3 , 3.5 , and 4 , respectively (Scheme 1), which is related to the order

Table 1 Crystal data and structure refinement parameters for complexes 1-3

\begin{tabular}{|c|c|c|c|}
\hline Complex & 1 & 2 & 3 \\
\hline CCDC & 1940269 & 1939982 & 1939983 \\
\hline Formula & $\mathrm{C}_{63} \mathrm{H}_{63} \mathrm{TbO}_{27}$ & $\mathrm{C}_{63} \mathrm{H}_{63} \mathrm{DyO}_{27}$ & $\mathrm{C}_{63} \mathrm{H}_{63} \mathrm{HoO}_{27}$ \\
\hline Crystal system & Trigonal & Trigonal & Trigonal \\
\hline Space group & $R 3$ & $R 3$ & $R 3$ \\
\hline$a / \AA$ & $27.187(1)$ & $27.165(9)$ & $27.072(9)$ \\
\hline$b / \AA$ & $27.187(1)$ & $27.165(9)$ & $27.072(9)$ \\
\hline$c / \AA$ & $7.617(8)$ & $7.652(1)$ & $7.637(1)$ \\
\hline$\alpha /^{\circ}$ & 90 & 90 & 90 \\
\hline$\beta /^{\circ}$ & 90 & 90 & 90 \\
\hline$\gamma /^{\circ}$ & 120 & 120 & 120 \\
\hline$V / \AA^{3}$ & $4876.2(4)$ & $4890.5(5)$ & $4847.6(5)$ \\
\hline$T / \mathrm{K}$ & $300(2)$ & $100(2)$ & $100(2)$ \\
\hline$Z$ & 3 & 3 & 3 \\
\hline$R_{\text {int }}$ & 0.040 & 0.070 & 0.029 \\
\hline GOF & 0.98 & 1.08 & 1.13 \\
\hline$F(000)$ & 2166 & 2169 & 2172 \\
\hline$D_{x} / \mathrm{mg} \mathrm{m}^{-3}$ & 1.442 & 1.441 & 1.456 \\
\hline$\mu, \mathrm{mm}^{-1}$ & 1.17 & 1.18 & 1.35 \\
\hline$R_{1} / \mathrm{w} R_{2}\left(I>2^{\sigma}(I)\right)^{a}$ & $0.0383 / 0.0934$ & $0.0425 / 0.1037$ & $0.0615 / 0.1504$ \\
\hline$R_{1} / \mathrm{w} R_{2}$ (all data) $^{b}$ & $0.0384 / 0.0935$ & $0.0428 / 0.1042$ & $0.0615 / 0.1504$ \\
\hline$\Delta \rho_{\max }, \Delta \rho_{\min }\left(\mathrm{e} \AA^{-3}\right)$ & $0.79,-0.57$ & $1.55,-1.65$ & $2.36,-0.63$ \\
\hline
\end{tabular}

of the lanthanide. In the case of $\mathrm{Ho}^{3+}$, it did not give crystalline compound, if maintaining the $\mathrm{pH}$ value between 3-3.5. That is, the $\mathrm{pH}$ value is important in the growth of single crystals, and a successive increase in the $\mathrm{pH}$ value is favorable for the complexes from $\mathrm{Tb}(\mathrm{III})$ to $\mathrm{Ho}(\mathrm{III})$. Similar $\mathrm{pH}$ dependent results of the lanthanide complexes were also reported. ${ }^{39}$ Complexes with heavy lanthanide ions (Er(III)-Lu(III)) are hard to obtain using the similar synthesis condition.

\subsection{IR spectra}

The IR spectra of d- $\mathrm{H}_{2}$ DTTA and complexes 1-3 are presented in Fig. S1. $\uparrow$ The peaks of each group are similar in the range of 4000-400 $\mathrm{cm}^{-1}$. The absorption bands in the IR spectra show the characteristic stretching vibrations of $\mathrm{O}-\mathrm{H}$ and $\mathrm{COO}^{-}$ groups. The broad bands at 3467,3459 and $3462 \mathrm{~cm}^{-1}$ indicate O-H stretching vibrations of the hydroxy groups and methanol molecules in the complexes $\mathbf{1 - 3 . . ^ { \mathbf { 4 0 } , 4 1 }}$ The strong bands at about 1734 and $1109 \mathrm{~cm}^{-1}$ are respectively assigned to the stretching vibrations of acyl $\mathrm{C}=\mathrm{O}$ and ester $\mathrm{C}-\mathrm{O} .{ }^{42}$ The characteristic peaks of the asymmetric and symmetric stretching vibrations of the carboxylate groups are present at about 1673 and $1338 \mathrm{~cm}^{-1}$, which were clearly weaker in complexes compared to the free $\mathrm{d}-\mathrm{H}_{2}$ DTTA ligand, suggesting that the carboxylate groups in the complexes had been coordinated to the metal cations. $^{\mathbf{4 3 , 4 4}}$ The structural features of complexes as deduced from IR closely match the results of the single crystal X-ray analyses.

\subsection{Structure description}

Crystal structure of $\left[\mathrm{Tb}(\mathrm{HDTTA})_{3}\left(\mathrm{CH}_{3} \mathrm{OH}\right)_{3}\right]_{n} \quad$ (1). Compounds 1-3 are isomorphic, thus only $\mathbf{1}$ is described here in detail. Single crystal X-ray diffraction shows that the complex 1 features a 1D propeller chain-like structure crystallizing in the trigonal $R 3$ space group. Each asymmetric unit contains 0.33 crystallographically independent $\mathrm{Tb}^{3+}$ ion, one HDTTA ${ }^{-}$ligand and one methanol molecule (Fig. 1). Each $\mathrm{Tb}^{3+}$ ion is ninecoordinated by six oxygen atoms $\left(\mathrm{O} 1, \mathrm{O} 1^{\mathrm{i}}, \mathrm{O} 1^{\mathrm{ii}}, \mathrm{O} 4^{\mathrm{iii}}, \mathrm{O} 4^{\mathrm{iv}}\right.$ and $\mathrm{O}^{\mathrm{V}}$ ) (symmetry code: $\mathrm{i}=1-y, x-y+1, z ; \mathrm{ii}=-x+y,-x+1, z$; iii $=x, y, z-1$; iv $=-y+1, x-y+1, z-1 ; \mathrm{v}=-x+y,-x+1, z-$ 1) from carboxyls of six HDTTA ${ }^{-}$ligands and three oxygen atoms $\left(09, \mathrm{O}^{\mathrm{i}}\right.$ and $\left.09^{\mathrm{ii}}\right)$ from three coordinated methanol molecules, exhibiting a tricapped trigonal prism geometry (Fig. 2). The d- $\mathrm{H}_{2}$ DTTA ligand is partly deprotonated and is a bidentate ligand, which shows a cis-conformation and adopts $\mu_{1,6}$-coordination mode via two monodentate carboxyl groups to link adjacent $\mathrm{Tb}^{3+}$ ions affording the infinite $1 \mathrm{D}$ propeller coordination polymer chain along the $c$ axis, with the $\mathrm{Tb} \cdots \mathrm{Tb}$ distance of 7.6178(5) $\AA$ (Fig. 3). The adjacent $\mathrm{Tb}^{3+}$ ions are grasped by three HDTTA ${ }^{-}$ligands with a three-ply mode, more tightly than the similar Ln-CPs based on another tartaric acid derivative, dibenzoyl tartaric acid $\left(\mathrm{H}_{2} \mathrm{DBTA}\right)$, which features $1 \mathrm{D}$ ladder or linear chain with a two-ply mode. ${ }^{25,45}$ The $\mathrm{Tb}-\mathrm{O}$ bond lengths and $\mathrm{O}-\mathrm{Tb}-\mathrm{O}$ bond angles fall in the range of 2.302(6)2.554(8) $\AA$ and $63.7(2)-140.3(3)^{\circ}$ (Table S1 $\dagger$ ), respectively, comparable to those reported in the literatures. ${ }^{4-48}$ The previously reported $\mathrm{Nd}^{3+}$ coordination compound with $1-\mathrm{H}_{2}$ DTTA 


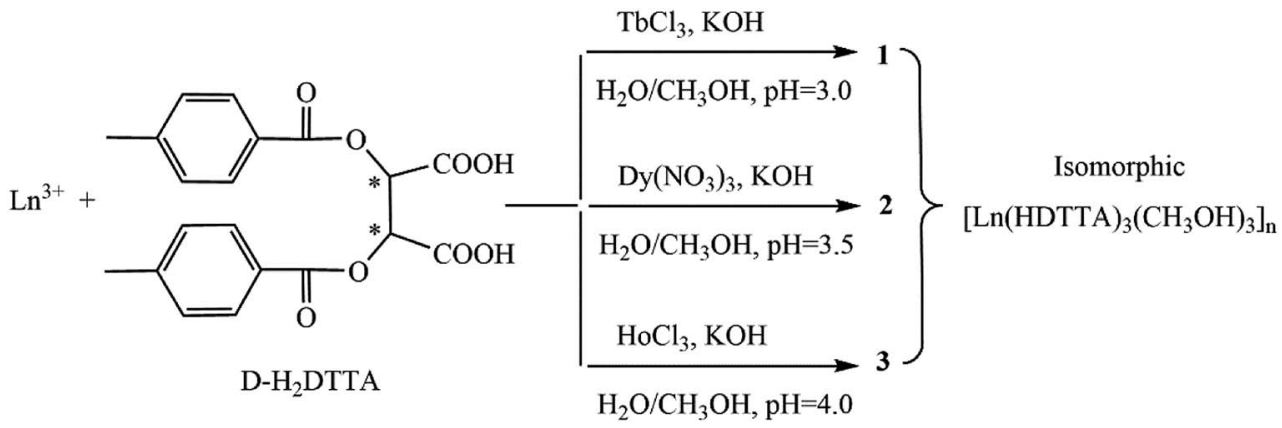

Scheme 1 Synthesis routes of complexes 1-3.

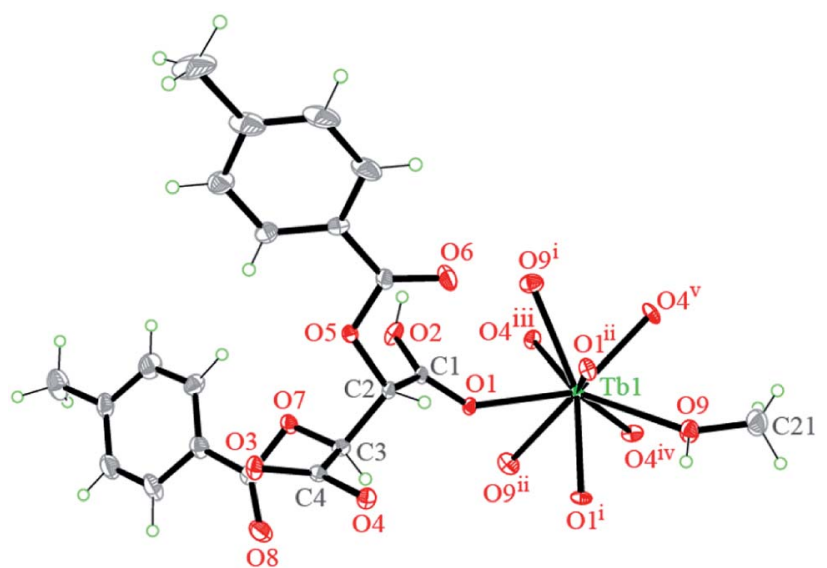

Fig. 1 Coordination environments of Tb cation and atomic labeling scheme in complex 1 (10\% thermal ellipsoids). Symmetry codes: (i) $=1$ $-y, x-y+1, z$; (ii) $=-x+y,-x+1, z$; (iii) $=x, y, z-1$; (iv) $=-y+1, x-$ $y+1, z-1 ;(v)=-x+y,-x+1, z-1$.

presents the similar unit formula $\left[\mathrm{NdL}_{3}\left(\mathrm{CH}_{3} \mathrm{OH}\right)_{3}\right]_{n}$ and 1D linear structure but different deprotonated mode of $1-\mathrm{H}_{2}$ DTTA. ${ }^{32}$

Notable are the patterns of snowflakes viewed from the crystallographic $c$-axis of complex $\mathbf{1}$, and the molecules are fully eclipsed (Fig. 4a). And it exhibits that a C18-H18 $\cdots \pi$ interaction with the centroid $(\mathrm{Cg})$ of the benzene ring (atoms C14C19), with a $\mathrm{H} 18^{\mathrm{vi}} \ldots \mathrm{Cg}^{\mathrm{iii}}$ distance of $2.55 \AA$ and a $\mathrm{C} 18^{\mathrm{vi}}-\mathrm{H} 18^{\mathrm{vi}} \ldots$ $\mathrm{Cg}^{\mathrm{iii}}$ angle of $155.2^{\circ}$ (Table S2 $\dagger$ and Fig. $4 \mathrm{~b}$ ). Complex 1 utilizes

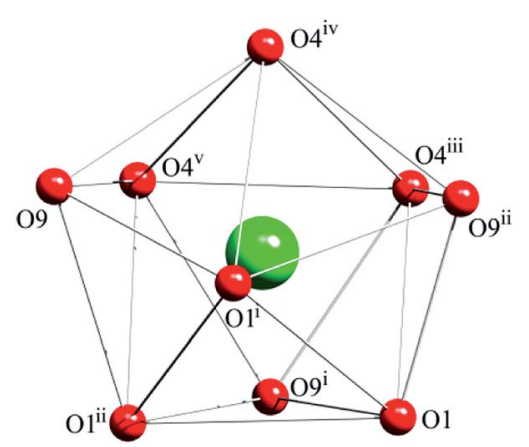

Fig. 2 Local coordination geometry of $\mathrm{Tb}^{3+}$ ion of complex 1 . Symmetry codes: (i) $=1-y, x-y+1, z$; (ii) $=-x+y,-x+1, z$; (iii) $=x$, $y, z-1$; (iv) $=-y+1, x-y+1, z-1$; (v) $=-x+y,-x+1, z-1$.

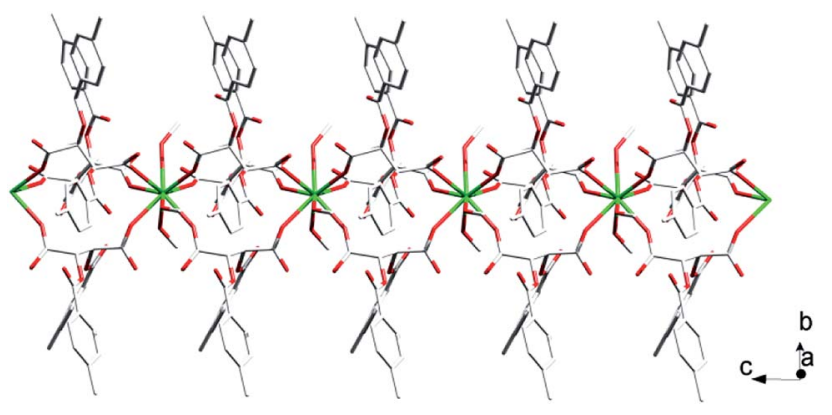

Fig. 3 The structure of 1D chain of complex 1 . All hydrogen atoms are omitted for clarity.

the $\mathrm{C}-\mathrm{H} \cdots \pi$ inter-actions to form a helical chain-like structure along the $c$ axis, as shown in Fig. 4c. The yellow line shows the location of the $3_{1}$ screw axis, with the pitch of screw 7.6178(5) $\AA$, and the height of one complete helix turn is $1 / 3$ translation of the $c$ axis.

\subsection{PXRD patterns and thermal analyses}

To check the phase purity, the samples of complexes 1-3 were characterized by PXRD. As can be seen in Fig. S2, $\uparrow$ the experimental PXRD patterns are almost identical to the calculated ones. The thermal stabilities have been investigated by TGA experiments under nitrogen atmosphere (Fig. S3†). Complexes 1-3 present the similar thermostability, so $\mathbf{1}$ is described here as a representative. The thermal gravimetric curve of $\mathbf{1}$ demonstrates that a weight of $6.7 \%$ in the temperature range $25-170{ }^{\circ} \mathrm{C}$ is lost, corresponding to the decomposition of three coordinated methanol molecules (calculated weight loss 6.8\%) and showing the distinct endothermic peak. Above that the linked ligands begin to decompose rapidly. TG results show that the number of solvent molecules is almost consistent with the results of elemental analyses and crystal structure analyses, and the 1D skeleton structure is stable up to about $200{ }^{\circ} \mathrm{C}$.

\subsection{UV-vis diffuse reflectance and circular dichroism spectrum}

CD and DRS spectra of compound 1 were measured in solid. The $\mathrm{CD}$ spectra measured in $\mathrm{KBr}$ pellets further verify the chirality of the complexes. As seen in Fig. 5a, the CD spectrum 


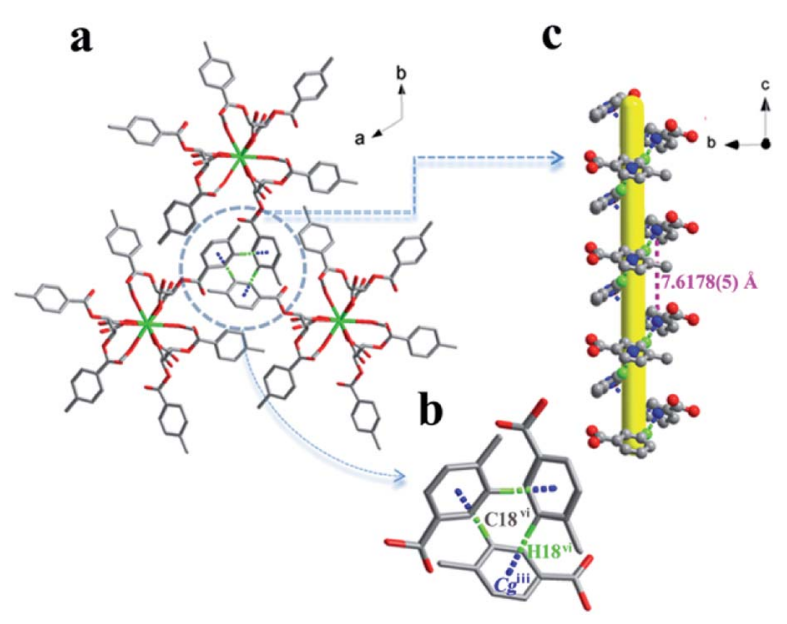

Fig. 4 (a) The pattern of snowflakes for 1 viewed along the crystallographic $c$ axis. (b) Local top viewed along the $c$ axis. (c) Local side viewed along the $b c$ plane of 1 , demonstrating the helical structure. $\mathrm{H}$ atoms not involved in hydrogen bonding have been omitted for clarity. Symmetry codes: (iii) $=x, y, z-1$; (vi) $=x, y, z-3$.

of complex 1 shows two positive Cotton effects at 260 and $211 \mathrm{~nm}$ due to the $\mathrm{n}-\pi^{*}$ transition in the carboxylic group. The chirality is consistent with that of d-tartaric acid which shows a single positive Cotton effect at $214 \mathrm{~nm}$ because of the different electronic nature of the carboxy group in the free acid and in its complex, and corresponds to the UV/vis DRS were measured for powder samples of complex 1 and $\mathrm{d}-\mathrm{H}_{2}$ DTTA, with the main absorption is in the range of $280-330 \mathrm{~nm}$ (Fig. 5b). ${ }^{\mathbf{4 9}, 50}$

\subsection{Luminescence properties}

It is a common sense to us that the carboxylate ligands can sensitize luminescence of trivalent lanthanide ions through an

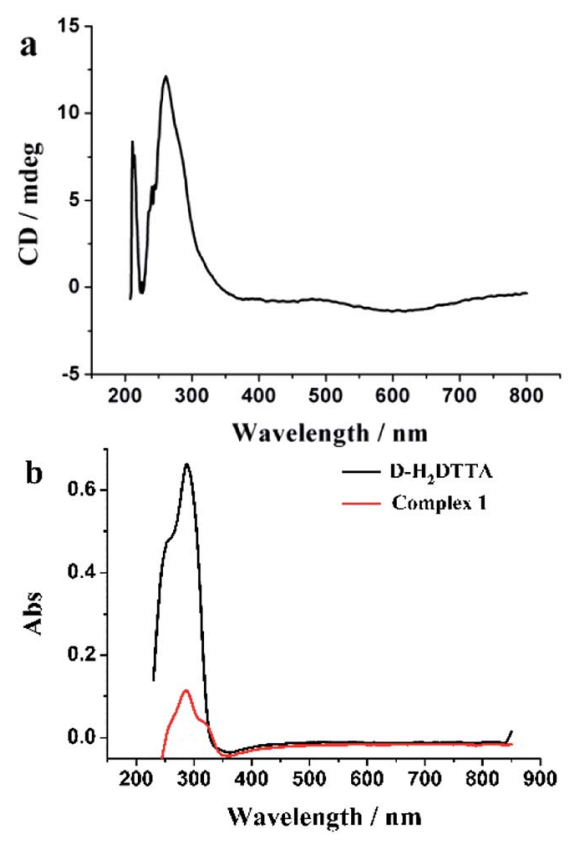

Fig. 5 (a) CD spectrum of complex 1. (b) The UV-vis DRS of complex 1 and $\mathrm{d}-\mathrm{H}_{2} \mathrm{DTTA}$. intramolecular energy-transfer process. Thus, the solid-state photoluminescent properties of $\mathrm{d}-\mathrm{H}_{2}$ DTTA and complexes were investigated at room temperature (Fig. 6). As shown in Fig. $6 \mathrm{~b}$, upon excitation at $300 \mathrm{~nm}$, the d- $\mathrm{H}_{2}$ DTTA ligand has a broad emission at $350 \mathrm{~nm}$, relating to the transition between the ground state and the excited states of the intramolecular charge-transfer process. ${ }^{51,52}$ Interestingly, complex 1 features columinescence of the ligand and $\mathrm{Tb}^{3+}$ ion (Fig. 6a), and dominated by characteristic peaks of the $\mathrm{Tb}^{3+}$ ion. In the emission range of 300-450 $\mathrm{nm}$, complex 1 keeps the same emission profile as the ligand with blue shift to $345 \mathrm{~nm}$, and in the range of 450-800 nm, it displays the sharp characteristic peaks of the $\mathrm{Tb}^{3+}$ ion at 488, 543, 584 and $620 \mathrm{~nm}$, which are attributed to the ${ }^{5} \mathrm{D}_{4} \rightarrow{ }^{7} \mathrm{~F}_{j}(j=6,5,4,3)$ transitions, respectively. The strongest peak at $543 \mathrm{~nm}$ derives from the ${ }^{5} \mathrm{D}_{4} \rightarrow{ }^{7} \mathrm{~F}_{5}$ transition, which is responsible for the bright green luminescence (Fig. S4a $\dagger$ ) with CIE color coordinates of 0.32 and 0.56 (Fig. 6a, inset). The decay lifetime curve of $\mathbf{1}$ shows the exponential decay with reasonable long lifetime of $1.169 \mathrm{~ms}$ (Fig. 6a, inset) and the relative quantum yield for 1 was $19.31 \%$, rendering this compound a promising candidate for the preparation of luminescent materials.

The emission spectrum of the dysprosium complex 2 is displayed in Fig. 6b; it exhibits broad fluorescence emission band of the ligand at $346 \mathrm{~nm}$ under excitation at $300 \mathrm{~nm}$. The observed blue-shift compared to d- $\mathrm{H}_{2}$ DTTA can be attributed to an intra-ligand $\pi-\pi *$ transition. Moreover, complex 2 shows two weak emission bands originating from the $\mathrm{f}-\mathrm{f}$ transitions of the $\mathrm{Dy}^{3+}$ ion in the visible region. The major emission bands at 479 and $572 \mathrm{~nm}$ correspond to the characteristic emissions originating from the ${ }^{4} \mathrm{~F}_{9 / 2} \rightarrow{ }^{6} \mathrm{H}_{15 / 2}$ and ${ }^{4} \mathrm{~F}_{9 / 2} \rightarrow{ }^{6} \mathrm{H}_{13 / 2}$ transitions of the $\mathrm{Dy}^{3+}$ ion, ${ }^{53-55}$ resulting in the white luminescence with CIE color coordinates of 0.29 and 0.26 (Fig. $6 \mathrm{~b}$, inset and Fig. $\mathrm{S} 4 \mathrm{~b} \dagger$ ). So far, Ln-CPs of single-component emitting white light remain rare to date, ${ }^{56-59}$ because luminescent emissions of Dy(III) complexes are usually weak. Comparable with 1, the emission arising from d- $\mathrm{H}_{2}$ DTTA ligand observed in the spectrum of 2 indeed indicates the incomplete energy transfer from $d$ $\mathrm{H}_{2}$ DTTA to the Dy ${ }^{3+}$ ion. ${ }^{19}$ A Dy-CP can be considered to emit both yellow (based on Dy) and blue (based on ligand) colors simultaneously. The BY dichromatic strategy is adopted to achieve white light emission in the balance of blue (B) and yellow (Y) colors, by changing the excitation wavelength. It is noteworthy that, this will provide an alternative approach to use Ln-CPs as single-phase white light emission for optical materials such as solid-state lighting, displays, biosensors, etc., which will make the preparation and operation easier, compared to the common strategy of using mixed-metal Ln-CPs (e.g. Eu and $\mathrm{Tb}$ ) for white light emission. ${ }^{54,57-59}$

Notably, the characterized peaks for $\mathrm{Ho}^{3+}$ ion in complex 3 were almost undetected. It exhibits the CIE chromaticity coordinate $(0.21,0.12)$, which only presents blue-shift emission bands of d- $\mathrm{H}_{2}$ DTTA at $345 \mathrm{~nm}$ under excitation at $300 \mathrm{~nm}$, caused by the poor sensitization efficiency of the ligand for the $\mathrm{Ho}^{3+}$ ion.

The aromatic tartaric acid derivatives have been confirmed to be suitable for the sensitization of the luminescence of $\mathrm{Ln}^{3+}$ 

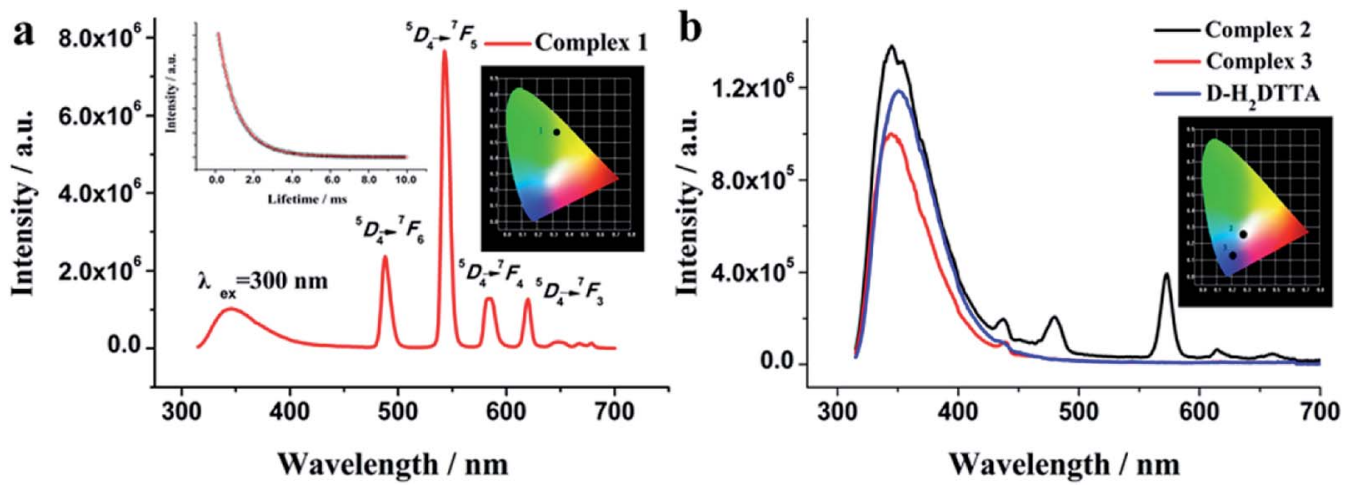

Fig. 6 The luminescence spectra of complexes $1-3$ and d- $\mathrm{H}_{2}$ DTTA ligand at $293 \mathrm{~K}$ in the solid state $\left(\lambda_{\text {ex }}=300 \mathrm{~nm}\right.$ ) (inset: the emission lifetime (left) and the CIE chromaticity diagram (right)).

ions. ${ }^{25,32,45}$ The characteristics of luminescence emission in our complexes reconfirm the antenna effect of d- $\mathrm{H}_{2}$ DTTA. Interestingly, complexes $\mathbf{1}$ and $\mathbf{2}$ display co-luminescence of ligand and $\mathrm{Ln}^{3+}$ ion, in which complex $\mathbf{1}$ features in the $\mathrm{Tb}^{3+}$ luminescence while complex 2 shows the combination luminescence of $\mathrm{d}-\mathrm{H}_{2} \mathrm{DTTA}$ and $\mathrm{Dy}^{3+}$; whereas complex 3 dominates the blue luminescence of d- $\mathrm{H}_{2}$ DTTA (Fig. $6 \mathrm{~b}$, inset and Fig. S4c广). The intensities of the energy transitions from $\mathrm{d}-\mathrm{H}_{2}$ DTTA ligand to the similar heavy lanthanide ions are different, possibly due to the different band gaps of various $\mathrm{Ln}^{3+}$ cations.

\subsection{Magnetic properties}

The temperature-dependent magnetic susceptibilities of the three complexes were measured in the range $2-300 \mathrm{~K}$ in an external magnetic field of $1000 \mathrm{Oe}$, and their magnetic behaviors are shown in Fig. 7. For 1, the $\chi_{\mathrm{m}} T$ value is $12.53 \mathrm{~cm}^{3} \mathrm{~mol}^{-1}$ $\mathrm{K}$ at $300 \mathrm{~K}$, which is slightly higher than the expected value of $11.82 \mathrm{~cm}^{3} \mathrm{~mol}^{-1} \mathrm{~K}$ for an isolated $\mathrm{Tb}^{3+}$ ion $\left({ }^{7} \mathrm{~F}_{6}, S=3, L=3 / 2, g\right.$ $=3 / 2$ ). The similar situations have also been reported in the mononuclear $\mathrm{Tb}^{3+}$ complexes. ${ }^{21,60}$ When decreasing the temperature, the $\chi_{\mathrm{m}} T$ product gradually decreases until $100 \mathrm{~K}$ and then decreases rapidly to $8.11 \mathrm{~cm}^{3} \mathrm{~mol}^{-1} \mathrm{~K}$ at $2 \mathrm{~K}$ (Fig. 7a). In the case of complex 2 shown in Fig. $7 \mathrm{~b}$, the $\chi_{\mathrm{m}} T$ value at room temperature is $12.89 \mathrm{~cm}^{3} \mathrm{~mol}^{-1} \mathrm{~K}$, which is slightly lower than the expected value $\left(14.17 \mathrm{~cm}^{3} \mathrm{~mol}^{-1} \mathrm{~K}\right)$ for one isolated $\mathrm{Dy}^{3+}$ ion $\left({ }^{6} \mathrm{H}_{15 / 2}, S=5 / 2, L=5, g=4 / 3\right)$. As the temperature decreases, the $\chi_{\mathrm{m}} T$ value decreases gradually to $12.50 \mathrm{~cm}^{3} \mathrm{~mol}^{-1} \mathrm{~K}$ at 100 $\mathrm{K}$, then it decreases rapidly to $10.43 \mathrm{~cm}^{3} \mathrm{~mol}^{-1} \mathrm{~K}$ at $2 \mathrm{~K}$. For complex 3 , the room temperature $\chi_{\mathrm{m}} T$ value is $13.76 \mathrm{~cm}^{3} \mathrm{~mol}^{-1}$ $\mathrm{K}$, which is close to the theoretical value of $14.07 \mathrm{~cm}^{3} \mathrm{~mol}^{-1} \mathrm{~K}$ for $\mathrm{Ho}^{3+}$ ion $\left({ }^{5} \mathrm{I}_{8}, S=2, L=6, g=5 / 4\right)$. Upon cooling, the value increases gradually to reach a maximum of $14.20 \mathrm{~cm}^{3} \mathrm{~mol}^{-1} \mathrm{~K}$ at $157 \mathrm{~K}$, and then decreases to $8.55 \mathrm{~cm}^{3} \mathrm{~mol}^{-1} \mathrm{~K}$ at $2 \mathrm{~K}$ (Fig. $7 \mathrm{c}$ ). These behaviors are ascribed to the depopulation of the low lying states $\left(m_{\mathrm{J}}\right.$ states) arising from the ${ }^{7} \mathrm{~F}_{6}\left(\mathrm{~Tb}^{3+}\right),{ }^{6} \mathrm{H}_{15 / 2}\left(\mathrm{Dy}^{3+}\right)$ and ${ }^{5} \mathrm{I}_{8}\left(\mathrm{Ho}^{3+}\right)$, and ground states split through the action of the crystal field (for these ions, the ground state is well below the first excited $\mathrm{J}$ state). ${ }^{61}$ Using the free-ion approach and the isotropic $(z)$ component of the susceptibility, the value of the zero-field splitting (ZFS), $\Delta$, was evaluated for each ion using the expressions in Scheme $\mathrm{S} 1$ in the ESI, $\dagger$ leading to $\Delta=$ $0.46(4) \mathrm{cm}^{-1}$ and $g=1.58(1) ; \Delta=0.22(1) \mathrm{cm}^{-1}$ and $g=1.35(2)$ and $\Delta=0.28(1) \mathrm{cm}^{-1}$ and $g=1.30(1)$ for $\mathrm{Tb}$, Dy and Ho, respectively. ${ }^{61,62}$ These values are in the range of those reported in the literatures. ${ }^{61,62}$

The molar magnetizations at $2 \mathrm{~K}$ for 1-3 do not get saturated in fields as high as $80 \mathrm{kOe}$, but rather, rise rapidly at low fields and then increase gently to $2.30,2.52$ and $2.46 \mathrm{~N} \beta$ at $80 \mathrm{kOe}$ (Fig. 7, inset), which are much lower than theoretical value of 9 $\mathrm{N} \beta$ for $\mathbf{1}$ (one free $\mathrm{Tb}^{3+}$ ion), $10 \mathrm{~N} \beta$ for $\mathbf{2}$ and $\mathbf{3}$ (one free $\mathrm{Dy}^{3+}$ or $\mathrm{Ho}^{3+}$ ion); ${ }^{63}$ such behavior can be attributed to the ligand-fieldinduced splitting of the Stark level, as well as magnetic anisotropy with a lower effective spin. ${ }^{64}$
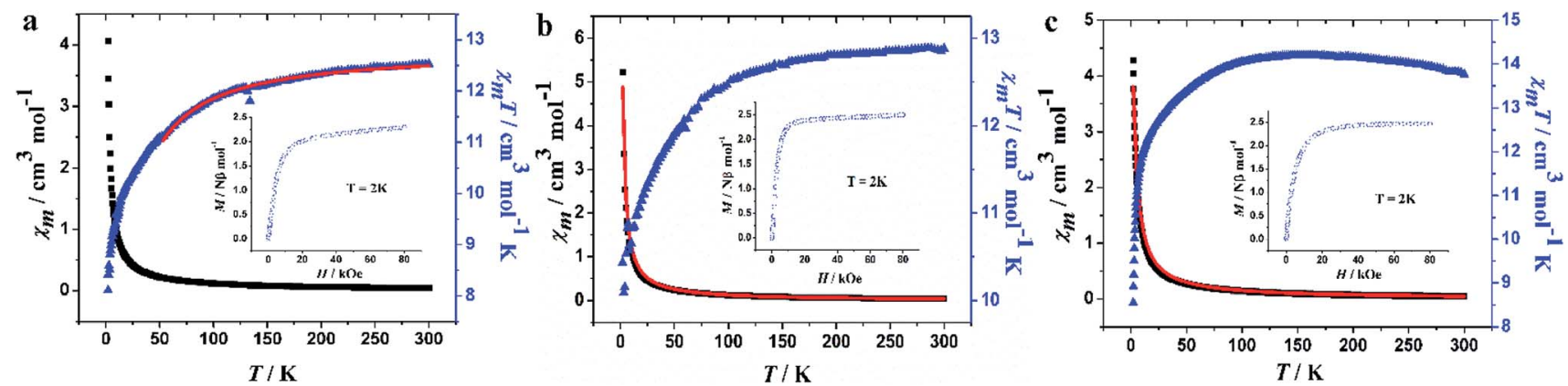

Fig. 7 Temperature dependence of $\chi_{m} T$ and $\chi_{m}$ versus $T$ of $1-3$. The solid red lines represent the fits obtained with equations in Scheme S1. $\dagger$ 
Moreover, alternating current (ac) susceptibility measurements for 1 were performed under a zero direct current field with a 3.0 Oe alternating current field to examine the dynamic spin behavior (Fig. S5 $\dagger$ ). No obvious $\chi_{\mathrm{m}}^{\prime}$ and $\chi_{\mathrm{m}}^{\prime \prime}$ signal are observed at frequencies from 10 to $1311 \mathrm{~Hz}$ at temperatures ranging from 2 to $22 \mathrm{~K}$, which can be attributed to the fast quantum tunneling effect for the complex; ${ }^{65}$ therefore, there is no slow relaxation of the magnetization for the complex. ${ }^{\mathbf{6 6}}$

\section{Conclusions}

In conclusion, three chiral coordination polymers featuring 1D spiral chain structures were prepared by $\mathrm{Ln}^{3+}$ ions $(\mathrm{Ln}=\mathrm{Tb}$, Dy and $\mathrm{Ho})$ and (+)-di- $p$-toluoyl-D-tartaric acid (d- $\mathrm{H}_{2}$ DTTA). Ditoluoyl-tartrate displays cis-conformation, and acts as a 1,4dicarboxylate linker in the complexes. The benzoylation of 2and 3-hydroxyl groups can hinder the coordination of hydroxyl and avoid forming of complicated entangled structures. The single crystal structures and the CD spectra confirm the chirality of the complexes. Photoluminescence spectra reveal that HDTTA $^{-}$anions are able to sensitize the luminescence of $\mathrm{Tb}^{3+}$ and $\mathrm{Dy}^{3+}$ ions in complexes 1 and 2, respectively. Moreover, complexes 1-3 exhibit magnetic properties that are characteristic for the considered lanthanide ions, which are dominated by the spin-orbit coupling and the ligand field perturbation with an almost negligible contribution of the exchange spin coupling between the lanthanide atoms, corresponding to the long Ln $\cdots$ Ln distances. The structures and properties of these coordination networks indicate that they may be good potential candidates for chiral, luminescent and magnetic multifunctional materials.

\section{Conflicts of interest}

There are no conflicts to declare.

\section{Acknowledgements}

We acknowledge Wei Cao (Shanxi University) and Zeng-Qiang Gao (BSRF) for the help of single crystal X-ray diffraction data collection and reduction. This work was supported by the Natural Science Foundation of China [Grant No. 21571118 \& 21671124]; the Natural Science Foundation of Shanxi Province [201701D121039]; the Fund for Shanxi “1331 Project” Key Innovative Research Team (1331KIRT); and the Undergraduate Research Training Plan Project of Shanxi University. A portion of this work was performed on the Scientific Instrument Center of Shanxi University of China.

\section{Notes and references}

1 K.-M. Wang, L. Du, Y.-L. Ma, J.-S. Zhao, Q. Wang, T. Yan and Q.-H. Zhao, CrystEngComm, 2016, 18, 2690-2700.

2 N. Wei, M.-Y. Zhang, X.-N. Zhang, G.-M. Li, X.-D. Zhang and Z.-B. Han, Cryst. Growth Des., 2014, 14, 3002-3009.

3 S. Biswas, H. S. Jena, S. Goswami, S. Sanda and S. Konar, Cryst. Growth Des., 2014, 14, 1287-1295.
4 X. Y. Xu, X. Lian, J. N. Hao, C. Zhang and B. Yan, Adv. Mater., 2017, 29, 1702298.

5 L. Zhou, Z.-G. Wang, H.-Y. Dong, K. Zhao, Y.-J. Hu, Z.-J. Gao, S.-N. Tie and H.-G. Zheng, Inorg. Chem. Commun., 2017, 78, $1-4$.

6 Y. Yang, K. Z. Wang and D. Yan, ACS Appl. Mater. Interfaces, 2017, 9, 17399-17407.

7 X. Yang, X. Lin, Y. Zhao, Y. S. Zhao and D. Yan, Angew. Chem., Int. Ed., 2017, 56, 7853-7857.

8 L.-N. Zheng, F.-H. Wei, H.-M. Hu, C. Bai, X.-L. Yang, X. Wang and G. Xue, Polyhedron, 2019, 161, 47-55.

9 J.-J. Yang, X.-Y. Yu, Y.-H. Luo, H. Zhang and W.-P. Gao, Inorg. Chem. Commun., 2015, 61, 16-20.

10 S. C. Chen, A. Q. Dai, K. L. Huang, Z. H. Zhang, A. J. Cui, M. Y. He and Q. Chen, Dalton Trans., 2016, 45, 3577-3589.

11 I. Oyarzabal, B. Fernández, J. Cepeda, S. Gómez-Ruiz, A. J. Calahorro, J. M. Seco and A. Rodríguez-Diéguez, CrystEngComm, 2016, 18, 3055-3063.

12 J. M. Seco, I. Oyarzabal, S. Perez-Yanez, J. Cepeda and A. Rodriguez-Dieguez, Inorg. Chem., 2016, 55, 11230-11248.

13 T. F. Jenkins, D. H. Woen, L. N. Mohanam, J. W. Ziller, F. Furche and W. J. Evans, Organometallics, 2018, 37, 38633873.

14 H. R. M. Silva, W. M. Faustino, E. E. S. Teotonio, H. F. Brito, O. L. Malta and M. C. F. C. Felinto, J. Lumin., 2019, 207, 182187.

15 J.-F. Song, H.-F. Wen, J.-J. Luo, Y.-Y. Jia, X.-Y. Zhang, L.-J. Su and R.-S. Zhou, J. Solid State Chem., 2019, 269, 43-50.

16 K.-X. Shang, S. Jing, D.-C. Hu, X.-Q. Yao, L.-H. Zhi, C.-D. Si and J.-C. Liu, Cryst. Growth Des., 2018, 18, 2112-2120.

17 Y.-L. Ma, L. Du and Q.-H. Zhao, Inorg. Chem. Commun., 2017, $77,1-5$.

18 J. Wu, H. Zhang and S. Du, J. Mater. Chem. C, 2016, 4, 33643374.

19 J. Zhao, G. H. Zhu, L. Q. Xie, Y. S. Wu, H. L. Wu, A. J. Zhou, Z. Y. Wu, J. Wang, Y. C. Chen and M. L. Tong, Dalton Trans., 2015, 44, 14424-14435.

20 N. Ahmed, C. Das, S. Vaidya, A. K. Srivastava, S. K. Langley, K. S. Murray and M. Shanmugam, Dalton Trans., 2014, 43, 17375-17384.

21 Y.-Q. Jia, S.-S. Feng, M.-L. Shen and L.-P. Lu, CrystEngComm, 2016, 18, 5344-5352.

22 L.-Y. Zhang, L.-P. Lu, M.-L. Zhu and S.-S. Feng, CrystEngComm, 2017, 19, 1953-1964.

23 Y.-Y. An, L.-P. Lu, S.-S. Feng and M.-L. Zhu, CrystEngComm, 2018, 20, 2043-2052.

24 C. Feng, J. W. Sun, P. F. Yan, Y. X. Li, T. Q. Liu, Q. Y. Sun and G. M. Li, Dalton Trans., 2015, 44, 4640-4647.

25 J.-W. Sun, S.-J. Li, P.-F. Yan, X. Yao and G.-M. Li, CrystEngComm, 2016, 18, 3079-3085.

26 T. J. Rutherford, P. A. Pellegrini, J. Aldrich-Wright, P. C. Junk and F. R. Keene, Eur. J. Inorg. Chem., 1998, 1677-1688.

27 K. Bernauer, F. Gretillat, H. Stoeckli-Evans and R. Warmuth, Helv. Chim. Acta, 1993, 76, 545.

28 A. Sellmer, H. Stangl, M. Beyer, E. Grunstein, M. Leonhardt, H. Pongratz, E. Eichhorn, S. Elz, B. Striegl, Z. Jenei-Lanzl, 
S. Dove, R. H. Straub, O. H. Kramer and S. Mahboobi, J. Med. Chem., 2018, 61, 3454-3477.

29 A. C. Smith, S. Cabral, D. W. Kung, C. R. Rose, J. A. Southers, C. N. Garcia-Irizarry, D. B. Damon, S. W. Bagley and D. A. Griffith, J. Org. Chem., 2016, 81, 3509-3519.

30 Z. S. Han, W. Shi and P. Cheng, Chin. Chem. Lett., 2018, 29, 819-822.

31 P. Bagi, K. Karaghiosoff, M. Czugler, D. Hessz, M. Kállay, M. Kubinyi, T. Szilvási, P. Pongrácz, L. Kollár, I. Timári, K. E. Kövér, L. Drahos, E. Fogassy and G. Keglevich, Heteroat. Chem., 2016, 27, 91-101.

32 W.-Y. Niu, C. Feng, N.-y. Fan, X.-Y. Wang, P.-F. Yan, J.-W. Sun and G.-M. Li, Synth. Met., 2016, 221, 319-325.

33 W. Y. Niu, P. F. Yan, Y. X. Li, G. H. An and G. M. Li, Sci. Adv. Mater., 2016, 8, 2189-2196.

34 W. Y. Niu, J. W. Sun, P. F. Yan, Y. X. Li, G. H. An and G. M. Li, Chemistry, 2016, 11, 555-560.

35 B. Casanovas, S. Speed, M. S. El Fallah, R. Vicente, M. FontBardia, F. Zinna and L. Di Bari, Dalton Trans., 2019, 48, 20592067.

36 Z. Otwinowski and W. Minor, Methods Enzymol., 1997, 276, 307-326.

37 G. M. Sheldrick, Acta Crystallogr., Sect. A: Found. Crystallogr., 2008, 64, 112-122.

38 G. M. Sheldrick, Acta Crystallogr., Sect. C: Struct. Chem., 2015, 71, 3-8.

39 Y.-F. Liu, G.-F. Hou, Y.-H. Yu, P.-F. Yan, J.-Y. Li, G.-M. Li and J.-S. Gao, Cryst. Growth Des., 2013, 13, 3816-3824.

40 N. Zhao, F. Sun, H. He, J. Jia and G. Zhu, Cryst. Growth Des., 2014, 14, 1738-1743.

41 F. Su, L. Lu, S. Feng and M. Zhu, CrystEngComm, 2014, 16, 7990-7999.

42 X.-L. Ma, Z.-X. Wang, X. He, M. Shao and M.-X. Li, Inorg. Chem. Commun., 2018, 92, 131-135.

43 L. Li, S. Wang, T. Chen, Z. Sun, J. Luo and M. Hong, Cryst. Growth Des., 2012, 12, 4109-4115.

44 M.-J. Zhou, B. Li, L. Liu, Y.-L. Feng and J.-Z. Guo, CrystEngComm, 2014, 16, 10034-10039.

45 Y. X. Li, S. J. Li, P. F. Yan, X. Y. Wang, X. Yao, G. H. An and G. M. Li, Chem. Commun., 2017, 53, 5067-5070.

46 J. Q. He, S. F. Xie, B. L. Lai, M. Yang, W. B. Chen, Y. Q. Zhang and W. Dong, Dalton Trans., 2018, 47, 14975-14984.

47 P. Kalita, J. Goura, J. Manuel Herrera Martínez, E. Colacio and V. Chandrasekhar, Eur. J. Inorg. Chem., 2019, 212-220.

48 R. G. Gámez-Heredia, A. Cruz-Enríquez, R. Aceves, H. Höpfl, M. Parra-Hake, R. E. Navarro and J. J. Campos-Gaxiola, Inorg. Chim. Acta, 2019, 486, 377-386.
49 X. Fang, T. M. Anderson and C. L. Hill, Angew. Chem., Int. Ed., 2005, 44, 3540-3544.

50 J. Gawroński and J. Grajewski, Org. Lett., 2003, 5, 3301-3303.

51 M. Pan, B. B. Du, Y. X. Zhu, M. Q. Yue, Z. W. Wei and C. Y. Su, Chem.-Eur. J., 2016, 22, 2440-2451.

52 Y. Zhang, K. Wang, G. Zhuang, Z. Xie, C. Zhang, F. Cao, G. Pan, H. Chen, B. Zou and Y. Ma, Chem.-Eur. J., 2015, 21, 2474-2479.

53 S. Shuvaev, V. Utochnikova, L. Marciniak, A. Freidzon, I. Sinev, R. Van Deun, R. O. Freire, Y. Zubavichus, W. Grunert and N. Kuzmina, Dalton Trans., 2014, 43, 31213136.

54 X. Q. Zhao, P. Cui, B. Zhao, W. Shi and P. Cheng, Dalton Trans., 2011, 40, 805-819.

55 C. Tedeschi, J. Azema, H. Gornitzka, P. Tisnes and C. Picard, Dalton Trans., 2003, 1738-1745.

56 Y. Xiao, S.-H. Wang, F.-K. Zheng, M.-F. Wu, J. Xu, Z.-F. Liu, J. Chen, R. Li and G.-C. Guo, CrystEngComm, 2016, 18, 721-727.

57 Q. Y. Yang, K. Wu, J. J. Jiang, C. W. Hsu, M. Pan, J. M. Lehn and C. Y. Su, Chem. Commun., 2014, 50, 7702-7704.

58 Y. Liu, M. Pan, Q.-Y. Yang, L. Fu, K. Li, S.-C. We and C.-Y. Su, Chem. Mater., 2012, 24, 1954-1960; M. Pan, W. M. Liao, S. Y. Yin, S. S. Sun and C. Y. Su, Chem. Rev., 2018, 118, 8889-8935.

59 M. Pan, W. M. Liao, S. Y. Yin, S. S. Sun and C. Y. Su, Chem. Rev., 2018, 118, 8889-8935.

60 W. Zhou, X. Feng, H. Ke, Y. Li, J. Tang and E. Wang, Inorg. Chim. Acta, 2013, 394, 770-775.

61 P. Farger, C. Leuvrey, M. Gallart, P. Gilliot, G. Rogez, J. Rocha, D. Ananias, P. Rabu and E. Delahaye, Beilstein J. Nanotechnol., 2018, 9, 2775-2787.

62 J. Cepeda, R. Balda, G. Beobide, O. Castillo, J. Fernandez, A. Luque, S. Perez-Yanez and P. Roman, Inorg. Chem., 2012, 51, 7875-7888.

63 J. L. Liu, Y. C. Chen and M. L. Tong, Chem. Soc. Rev., 2018, 47, 2431-2453.

64 J. Tang, I. Hewitt, N. T. Madhu, G. Chastanet, W. Wernsdorfer, C. E. Anson, C. Benelli, R. Sessoli and A. K. Powell, Angew. Chem., Int. Ed., 2006, 45, 1729-1733.

65 S. P. Bera, A. Mondal, S. Roy, B. Dey, A. Santra and S. Konar, Dalton Trans., 2018, 47, 15405-15415.

66 J. Wang, M. Zhu, C. Li, J. Zhang and L. Li, Eur. J. Inorg. Chem., 2015, 1368-1375. 